\title{
Key Drivers of the Emergency Capabilities of Integrated Elderly Services Supply Chains
}

Jingshi He, Dongguan Polytechnic, China*

Jiali Zhu, Dongguan Polytechnic, China

\begin{abstract}
This study investigated integrated elderly care services supply chains using a combination of decisionmaking trial and evaluation laboratory (DEMATEL), interpretative structural modeling (ISM), and the technique for order preference by similarity to ideal solution (TOPSIS). The research identifies the key factors related to the emergency response capabilities of elderly service supply chains and the most important ways to improve them. The integrated DEMATEL-ISM-TOPSIS method provides new theoretical support for the management of elderly care service supply chains.
\end{abstract}

\section{KEYWORDS}

DEMATEL, Elderly Services Supply Chain, Emergency Capability, Emergency Services Supply Chain, Integrated Supply Chain, ISM, TOPSIS

\section{INTRODUCTION}

Elderly services have become a focus of social concern in the context of a severe global aging problem and falling birth rate. The aging of the population in China is worse than that in other countries. One of the key reasons is the one-child policy implemented in 1980, which has greatly reduced China's overall fertility rate and changed Chinese people's concept of fertility. The challenges faced by China in social security and care for the elderly provide opportunities for the elderly care industry and other related industries (He \& Wang, 2019). The elderly care service industry, driven by the growth in demand, is an emerging industry, which has formed a healthy supply chain integrating services, care products and equipment, information technology, financing, care system integration, and other resources for the elderly. Community-based, institutional, and home-based elderly care services are the three most important elderly care service models in China. However, all are inseparable from the cooperation between upstream and downstream enterprises in the supply chain. From the perspective of the supply chain, the elderly care service industry should pay attention to the construction of upstream and downstream partner networks and should focus on the partnership and network of all stakeholders (Supromin \& Choonhakhlai, 2019). At present, the elderly care service market has formed a service chain with a clear structure and an explicit subject. The elderly services market and industrial supply chain in China are in the initial stage: the market has not yet formed a scale, the utilization rate of resources is low, and resources are unstable. The elderly, the object of elderly care services, are characterized by many sudden diseases and diverse needs for their care (Menghi et 
al., 2019). The diversity and personalization of health care services for the elderly are of paramount importance. The requirements for elderly care service products are more complex than other types of services and products, leading to higher demand fluctuations (Zhao, 2020). The shortage of raw materials in the upstream and downstream supply chain, sudden changes in service demand, quality problems, and mismatches in demand may all cause supply chain risks and affect the stability of the supply chain (Raghunath \& Devi, 2018; Sharma et al., 2017). Public safety and health incidents, unexpected social security incidents, and natural disasters will also cause increased fluctuations in the supply chain. Society has realized the importance of emergency management after the COVID-19 outbreak. Once an emergency occurs, it causes great personal injury to the receivers of elderly care services. As social public safety and hidden dangers receive increasing attention, emergency management has become a point of discussion for society and scholars alike. Research showed that $71.3 \%$ of respondents have low response capability when emergencies occur in elderly care institutions (Kim \& Bae, 2020). The analysis of and research on the emergency capability of elderly care services is beneficial to discover its weaknesses and implement targeted measures for prevention. Therefore, emergency management in the elderly services supply chain should be a concern for all sectors of society in both macro and micro views. The current research on emergency management for the elderly mainly focuses on emergency medical treatment (Kim \& Bae, 2020; Lee et al., 2017; Platts-Mills et al., 2010). Relevant research identifying and understanding the emergency response capability of the elderly care services industry from the perspective of the supply chain is still lacking. The present research intends to build an indicator system for the emergency response capabilities of those in the elderly care services supply chain, which can make up for the lack of research in this area. In a practical sense, this research can provide a theoretical reference and basis for elderly care service integrators (SIs) and participating companies to improve their supply chain capabilities and ensure the stability of the elderly care services supply chain.

For the model and method, this research will construct evaluation indicators of the elderly services' emergency capabilities from the perspective of the supply chain for the first time and propose a new method, integrating the decision-making trial and evaluation laboratory (DEMATEL), interpretative structural modeling (ISM), and technique for order preference by similarity to ideal solution (TOPSIS) methods into the DEMATEL-ISM-TOPSIS method to analyze and evaluate the attributes of various factors of the emergency capability of the elderly services supply chain. This method combines the main advantages of the three methods to simplify the calculation process. The integrated DEMATEL-ISM-TOPSIS method is a hybrid and diversified decision-making evaluation method and is an innovative research methodology.

The basic framework of this article is as follows. First, this research builds an operational model of the elderly care services supply chain and proposes an operational model of the emergency supply chain to form an index system of the emergency capability of the former. Second, through the DEMATEL-ISM-TOPSIS model, this research analyzes and evaluates the relationship between the elements of emergency capability, as well as their strengths and importance; constructs an ISM model; and explores which factors of emergency capability for the elderly are influential at the surface-level and which low-level. Finally, this research evaluates the emergency response capabilities of elderly care service institutions and provides management guidelines for elderly care services to manage their emergency response capabilities.

\section{LITERATURE REVIEW}

\subsection{Elderly Care Services Supply Chain}

The supply chain theory was first applied in the industrial field. With the intersection of disciplines, numerous subresearch fields have been derived, such as the cross-study of the supply chain and big data (Chehbi-Gamoura et al., 2021), and the research derived from the combination of the traditional 
supply chain and the service industry, such as the logistics, (Liu et al., 2018), medical (Tooranloo et al., 2018), and tourism (Huang, 2018) services supply chains. Supply chains are network chains with service output as their core. They integrate various resources among suppliers, service providers (SPs), and consumers through service production and delivery to consumption; transforms them into core or supporting services; and finally transmits them to customers (Baltacioglu et al., 2007). The elderly care services supply chain is a multi-level network composed of an elderly care SI and an elderly care SP (Zhao, 2020). The sustainability of the elderly care services supply chain can be achieved through flexible contracts (Zhao, 2021), and a set of key performance indicators are needed to evaluate them (Mezouar \& Afia, 2018). Third-party agencies can integrate resources for elderly care services to achieve resource complementarity and improve service satisfaction (Gao \& Zhou, 2020). In addition, the elderly care services supply chain also involves reverse logistics (Putthinoi et al., 2015).

The supply-chain operations reference (SCOR) model is a concept for managing the advanced business operation technology established by the Supply Chain Council (SCC) to improve the competitiveness and cooperation between upstream and downstream trading partners. The SCOR model covers activities from demand confirmation to product delivery, such as planning, purchasing, production, delivery, sales, and returns (Stewart, 1997), and is further subdivided into process categories, elements, tasks, and activities (Cao et al., 2018; Ntabe et al., 2015). As the traditional SCOR model does not include sales, design, or product development, it cannot fully describe the business framework components, so the SCC later proposed the design-chain operations reference (DCOR) and the customer chain operation reference (CCOR) models. The DCOR model spans activities between customer demand and product design or specifications to meet customer demand, and the CCOR model covers activities related to establishing and maintaining customer relationships, identifying customer needs, and providing product support. The integrated business framework model that comprises DCOR, CCOR, and SCOR extends the connotations of the traditional SCOR model. It can be more widely used in various service industries rather than being limited to traditional industrial fields; thus, it can be called the integrated SCOR.

Supply chain innovation has become important in today's competitive world (Mandal, 2016). Using supply chain theory to analyze the elderly care services industry is an emerging area of research. At present, there is no literature on the emergency capability of the elderly care services supply chain. Therefore, this research is a crucial supplement to the elderly care services supply chain theory.

\subsection{Emergency Capability of the Elderly Care Services Supply Chain}

Compared to young people, elderly people use emergency medical services (EMS) at a high rate (PlattsMills et al., 2010). Fall-related injuries in the elderly are the main reason for them to use EMS (Lee et al., 2017). During a stay in a nursing home, an elderly person's health may suddenly deteriorate, so it is very important to monitor it. With the rapid advancement of health informatization, intelligent nursing home systems have become prevalent (Cui et al., 2020). Failure to effectively provide emergency information about the elderly may adversely affect their well-being (Gill et al., 2016). Developing a geriatric care management system based on the Internet of Medical Things (IoMT) can monitor the health of the elderly to respond to care plans in a timely manner and improve the efficiency of care and the quality of medical services (Gill et al., 2016; Tang et al., 2019). Influenced by COVID-19, the artificial intelligence-based electronic health system for elderly care is conducive to improving the overall quality of home care services (Lam et al., 2021), and the use of telemedicine services and online healthcare systems can also benefit both doctors and patients (Iyamu \& Shaanika, 2020; Rahi, et al., 2021).

In disaster emergency supply chain management, the characteristics of non-cooperation between members, interruption of the command chain, abuse of relief supplies, lack of information sharing, mistrust, and lack of coordination have seriously affected the assistance work of the supply chain (Dwivedi et al., 2018). Emergency relief supply chain design is important, as it affects the overall performance of emergency management activities significantly (Hong et al., 2015). Design elements, 
inventory, transportation, capacity, and technical elements should be considered in the design of the supply chain (Melnyk et al., 2014). The capability of the emergency supply chain is affected by cost, response time, and spare capacity of the backup supplier (Thomas \& Mahanty, 2020). The effective operation of emergency logistics and rapid response to the emergency needs of disaster areas are crucial in disaster emergency rescue services (Ji \& Zhu, 2012). A pre-deployed warehouse network for emergency response can reduce cost and response time (Jahre et al., 2016).

The current research on emergency management of the elderly mainly emphasizes the field of emergency medical treatment, and there is no literature analyzing the emergency response capability of the elderly care services from the perspective of the service supply chain. The research showed that $71.3 \%$ of the respondents have low emergency response capability when emergencies occur in elderly care institutions (Kim \& Bae, 2020). Analyzing the factors of the elderly care services supply chain will help elderly care service organizations improve their emergency response capability and ensure the stability of the elderly care services supply chain. At present, there is no literature on the emergency response capability of the elderly care services supply chain. Therefore, this research has great supplementary significance to the emergency response theory of the elderly care services supply chain, which has important practical significance for the improving the emergency management capability of the elderly care services supply chain.

\subsection{Literature on Evaluation Methods}

The methods used to evaluate emergency capability, such as the analytic network process (ANP), fuzzy comprehensive evaluation method, and grey clustering method, focus on the evaluation of decision-making units (DMUs) but lack the attribute analysis of each indicator element. Those methods cannot analyze the strength, importance, and structural hierarchical relationship of the factors. System dynamics methodology and structural modeling can analyze the attributes and logical relationships of factors, but they cannot evaluate the overall evaluation unit. This research not only analyzes the strength, importance, and structure of the factors but also evaluates the overall evaluation unit, so a hybrid integration method is needed.

In past research, researchers use the integrated DEMATEL-ISM method to analyze factor evaluation, which can avoid the shortcomings of the two methods. The integrated DEMATEL-ISM method is used to analyze factors of DMUs in multiple fields, such as the obstacles to sustainable transportation in Indian inland waterways (Trivedi et al., 2021), the factors affecting the safety of coal mine production (Wang et al., 2018), the obstacles to the implementation of e-waste management practices (Kumar \& Dixit, 2018), and the causes of accidents in the gas pipeline network (Li et al., 2019).

The DEMATEL method uses graph theory and matrix relationships to analyze the causal relationship between various factors of the decision matrix. This method is used to screen the main elements of complex problems and simplify the process of system structure analysis. The DEMATEL method can be used to calculate the degree of influencing and being influenced among the factors of the decision-making evaluation matrix (Kilic \& Yalcin, 2020; Yazdi et al., 2020) to obtain the relationship degree between various indicators of the decision-making evaluation matrix by calculating the centrality degree and the causality degree. By establishing the central and causal factors of the emergency capability of the elderly care services supply chain, the importance of each factor on the quality of elderly care services can be obtained. The ISM method can deconstruct the complex and disordered relationship between these factors in the decision matrix system into a clear, multi-level hierarchical structure. However, DEMATEL and ISM also have shortcomings that cannot be ignored. The DEMATEL method cannot reveal the inner logical structure within each factor. The factors of the decision matrix stratified by the ISM method in the same level have no primary or secondary relationship.

The DEMATEL method can be used to explore the causal relationship between evaluation factors, and the model calculation requires a small sample size. The ISM method can be used to explore the 
hierarchical logical relationship between factors. But both of these models are used to analyze and evaluate factors, and they cannot evaluate and rank the entire DMU. If it is necessary to evaluate and rank DMUs, they are often used in combination with other methods, such as combining DEMATEL with ANP, to evaluate and rank the DMUs (Raut et al., 2021) and combining DEMATEL and TRIZ to evaluate key points (Chang et al., 2017).

The TOPSIS method can rank multiple alternatives according to their similarity or proximity to the ideal solution. In past research, the TOPSIS model has been widely used in various fields to rank DMUs. For example, Okwu and Tartibu (2020) used the TOPSIS method to rank suppliers to make decisions. Leung et al. (2021) combined the fuzzy, ANP, and TOPSIS methods to rank food retailers. Some scholars also combined DEMATEL and TOPSIS to evaluate supplier performance (Mohammed et al., 2021) or used a combination of DEMATEL, ANP, and TOPSIS to rank competing solutions (Alam-Tabriz et al., 2014).

This research analyzes the factors in the emergency capability of the elderly care services supply chain; analyzes and evaluates the causal relationship between emergency capability elements, their strength, and importance; and explores which factors of the emergency capability of services for the elderly are surface-level and which are bottom-level factors. Using the DEMATEL-ISM method, the structural hierarchical relationship and master-slave logical relationship of the factors in the emergency capability of various elderly care services are clarified. Combining these with TOPSIS to evaluate the emergency capability of the DMU of an elderly care institution, the evaluation score is obtained. The integrated DEMATEL-ISM-TOPSIS method is a hybrid and diversified decisionmaking evaluation method and is an innovative research methodology.

\section{MODEL AND EVALUATION INDEX}

\subsection{Operation Model of the Elderly Care Services Supply Chain}

The current situation and welfare system for the elderly in China are very different to those in other countries; therefore, the development of the elderly care industry cannot copy them. Communitybased, institutional, and home-based elderly care services are the three most important elderly care service models in China. The institutional elderly care service model refers to the elderly living in third-party institutions, such as nursing homes, welfare homes, and hospitals, where professional service organizations provide nursing services for them. This model is widely adopted globally. Community-based elderly care services use the community as a platform from which to provide day care centers, eateries, and supermarkets for the elderly, among other services. The elderly can therefore live with their families and care services provided by the community. Home-based elderly care services regard the family as the core. The elderly live at home, and professionally trained service personnel or dedicated agencies will come to provide elderly care services.

In the elderly care services supply chain, the elderly are the end-consumers. Community-based elderly care service institutions and third-party elderly care organizations are the SIs of the supply chain. They are the core of the supply chain and are responsible for the integration and matching of demand to resources. The upstream of the elderly care services supply chain includes housekeeping, life care, spiritual comfort, medical care, and cultural and entertainment SPs. A widely accepted structure of the service supply chain is: "SP-SI-Customer" (Baltacioglu et al., 2007; Liu et al., 2019). The operational model of the elderly care services supply chain, from the supply of elderly care services to their consumption, is shown in Figure 1. The elderly care service process is divided into three basic stages: service supply, integration, and implementation. In the integration stage, the core enterprise integrates elderly care service information, funds, and products; develops and designs elderly care service projects; and provides a complete set of integrated service solutions for the elderly. In the implementation stage, the elderly purchase old-age service products and projects. These can be divided into government-purchased and self-financed projects. In the three-stage process of supply chain operation, there are a series of activities, such as service planning, demand tracking, 
service feedback, information flow, logistics, and capital flow, all of which are set to achieve the goal of caring for the elderly.

Figure 1. Operational model of the elderly care services supply chain

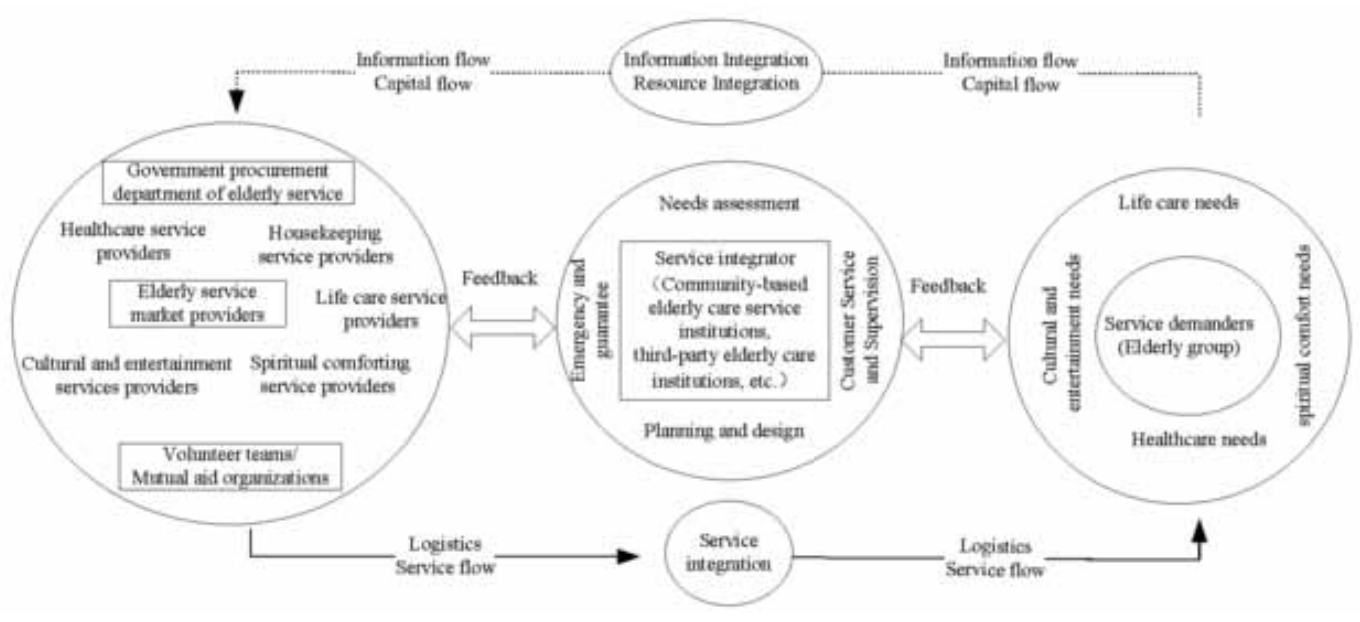

\subsection{The Emergency Supply Chain Model and The Evaluation Indicators of the Emergency Capability of Elderly Care Services}

Emergency rescue supply chain design is an important strategic decision (Hong et al., 2015), and customer-centricity is the most crucial factor in the improvement of supply chain quality management (Chau et al., 2021). According to the integrated supply chain model comprising DCOR, CCOR, and SCOR, the modern supply chain operational model includes planning, supply, delivery, and feedback. Combining the characteristics of the elderly care service industry and supply chain, based on the theory of the integrated supply chain, this article outlines the emergency supply chain model of elderly care services, including emergency design, planning, supply, delivery, and feedback. The operational model of the emergency supply chain for elderly services is proposed in Figure 2 . Based on this, the emergency capability indicator system of the elderly services supply chain is proposed in Table 1. After the initial questionnaire design was completed, the research team surveyed a total of 86 respondents from 11 elderly care service organizations located in Guangzhou, Shenzhen, and Dongguan. Among the respondent were employees of elderly care service institutions, customers of elderly care service institutions, scholars from universities and research institutions, officials of government departments for elderly services, and family members of the elderly. Initially, the survey team established an evaluation system of 30 indicators. After discussion, it deleted some indicators that the interviewees did not understand clearly and others that were difficult for them to score, and finally retained 14 evaluation indicators, as shown in Table 1 .

\section{METHODOLOGY}

This paper propose an integrated DEMATEL-ISM-TOPSIS method to analyze various factors affecting the capability of the elderly services supply chain, aiming to obtain the weight of each evaluation factor and the total DMU score to evaluate and rank the emergency capability of elderly services. The process diagram of the methodology is shown in Figure 3. 
Figure 2. Operation model of the emergency supply chain for elderly services

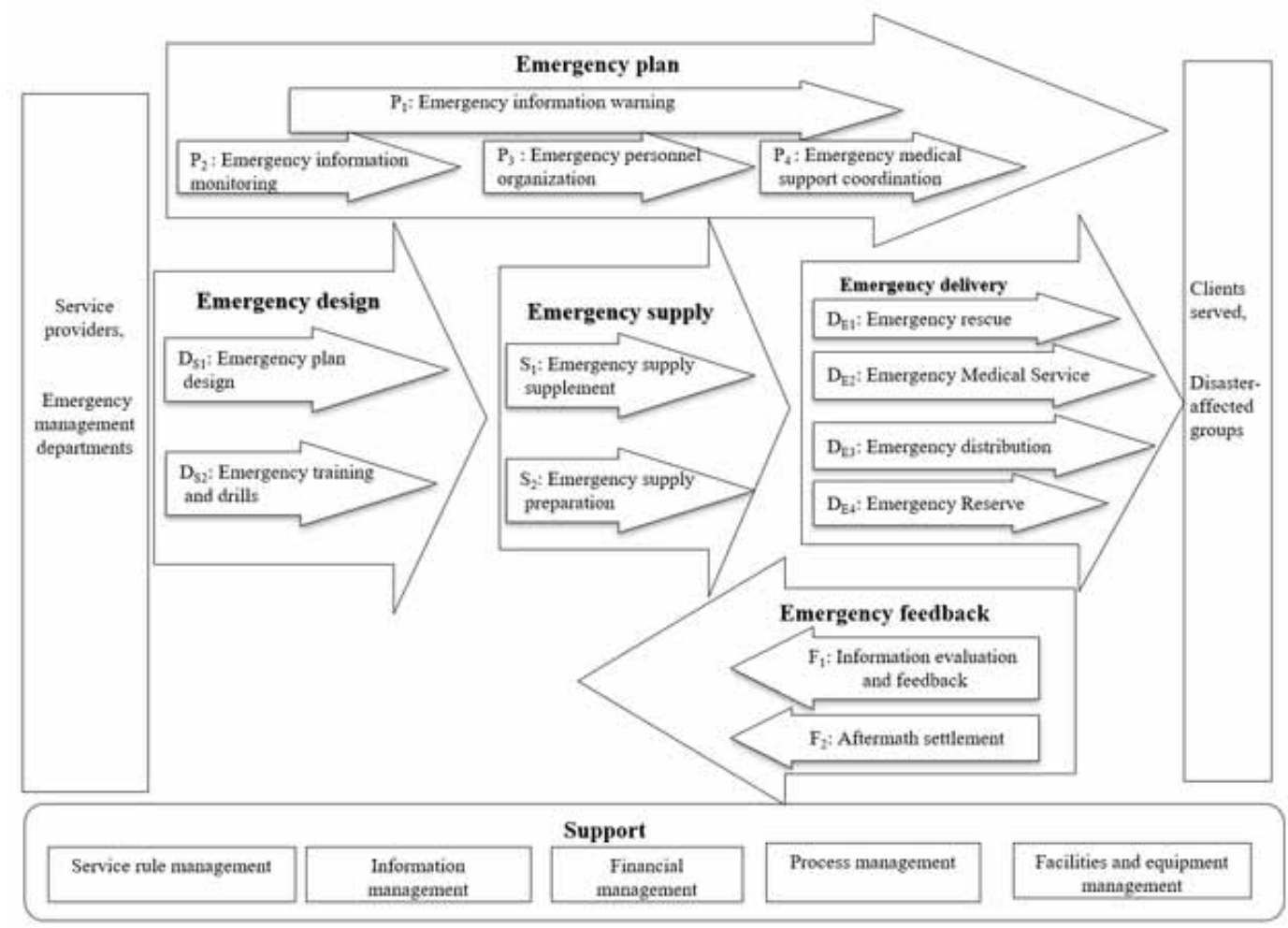

Step 1: Establish initial direct influence matrix

Assuming that the scales $0,1,2,3,4$, and 5 represent the range from "no influence" to "very high influence," experts are asked to propose the influences of these factors based on pairwise factor comparisons in terms of the degree and directions of influence. Matrix $X \quad X$ represents the interaction between the factors of the emergency capability of the elderly services supply chain, and $x_{i j} x_{i j}$ represents the degree to which the factor $S_{i} S_{i}$ affects the factor $S_{j} S_{j}$.

$X=\left[\begin{array}{cccc}x_{11} & x_{12} & \ldots & x_{1 n} \\ x_{21} & x_{22} & \ldots & x_{2 n} \\ \ldots & \ldots & \ldots & \ldots \\ x_{n 1} & x_{n 2} & \ldots & x_{\mathrm{nn}}\end{array}\right] X=\left[\begin{array}{cccc}x_{11} & x_{12} & \ldots & x_{1 n} \\ x_{21} & x_{22} & \ldots & x_{2 n} \\ \ldots & \ldots & \ldots & \ldots \\ x_{n 1} & x_{n 2} & \ldots & x_{\mathrm{nn}}\end{array}\right]$.

Step 2: Establish the comprehensive influence matrix

By normalizing the initial direct influence matrix, the normalized direct influence matrix $X^{1}$ $X^{1}$ is obtained by Eq. (1), and the comprehensive influence matrix $T$ T is obtained through the calculation of matrix $X^{1} \quad X^{1}$ by Eq. (2): 
Table 1. Evaluation indicators

\begin{tabular}{|c|c|c|}
\hline $\begin{array}{l}\text { First-level } \\
\text { indicators }\end{array}$ & Second-level indicators & Detailed indicator explanation \\
\hline \multirow{2}{*}{$\begin{array}{l}\text { Emergency } \\
\text { design } \\
\text { capability }\end{array}$} & $\begin{array}{l}S_{1}: \text { Design of emergency } \\
\text { response plan }\end{array}$ & $\begin{array}{l}\text { Whether the emergency response plan is comprehensive and operable and } \\
\text { whether there are multiple emergency plans }\end{array}$ \\
\hline & $\begin{array}{l}S_{2}: \text { Emergency plan } \\
\text { training and drills }\end{array}$ & $\begin{array}{l}\text { Whether the emergency drills take the particularity of service objects into } \\
\text { account, whether the emergency plan achieves training for all staff, and } \\
\text { whether the emergency plan and drills have good effect }\end{array}$ \\
\hline \multirow{4}{*}{$\begin{array}{l}\text { Emergency } \\
\text { planning } \\
\text { capability }\end{array}$} & $\begin{array}{l}S_{3}: \text { Early warning } \\
\text { capability of emergency } \\
\text { information }\end{array}$ & $\begin{array}{l}\text { The ability to collect and analyze information and give early warning of } \\
\text { the potential sources of danger in emergencies }\end{array}$ \\
\hline & $\begin{array}{l}S_{4}: \text { Emergency } \\
\text { information monitoring } \\
\text { capability }\end{array}$ & $\begin{array}{l}\text { The ability of elderly services to monitor the risk factors and information } \\
\text { in emergencies and release timely information }\end{array}$ \\
\hline & $\begin{array}{l}S_{5}: \text { Emergency personnel } \\
\text { organization capability }\end{array}$ & $\begin{array}{l}\text { Whether the emergency rescue team has the ability to coordinate, } \\
\text { communicate, and command in multiple departments; whether it is } \\
\text { organized and responds in a timely manner; and whether there is a } \\
\text { backup plan and backup rescue personnel when the rescue manpower is } \\
\text { insufficient }\end{array}$ \\
\hline & $\begin{array}{l}S_{6}: \text { Emergency medical } \\
\text { coordination capability }\end{array}$ & $\begin{array}{l}\text { The ability to cooperate with other primary health and medical } \\
\text { institutions, the ability to coordinate and communicate with the social } \\
\text { security department, and the ability to urgently communicate with the } \\
\text { elderly care material suppliers }\end{array}$ \\
\hline \multirow{2}{*}{$\begin{array}{l}\text { Emergency } \\
\text { supply } \\
\text { capability }\end{array}$} & $\begin{array}{l}S_{7}: \text { Emergency supply } \\
\text { replenishment rate }\end{array}$ & $\begin{array}{l}\text { In the face of emergencies, whether emergency supplies can be mobilized } \\
\text { quickly and in time and whether they can be quickly replenished when the } \\
\text { reserves are insufficient }\end{array}$ \\
\hline & $\begin{array}{l}S_{8}: \text { Emergency supply } \\
\text { preparation capability }\end{array}$ & $\begin{array}{l}\text { When suppliers are in short supply and cannot meet the needs of } \\
\text { emergencies, whether there are emergency plans for procurement and } \\
\text { supply and backup suppliers to quickly replenish goods }\end{array}$ \\
\hline \multirow{4}{*}{$\begin{array}{l}\text { Emergency } \\
\text { delivery } \\
\text { capability }\end{array}$} & $\begin{array}{l}S_{9}: \text { Emergency rescue } \\
\text { response capability }\end{array}$ & $\begin{array}{l}\text { Whether the emergency service and emergency medical referral can } \\
\text { respond quickly }\end{array}$ \\
\hline & $\begin{array}{l}S_{10}: \text { Emergency medical } \\
\text { service capability }\end{array}$ & $\begin{array}{l}\text { Whether the commonly used emergency medical equipment and materials } \\
\text { are reserved and whether the medical treatment is carried out in a timely } \\
\text { manner in emergencies }\end{array}$ \\
\hline & $\begin{array}{l}S_{11}: \text { Emergency } \\
\text { distribution capability }\end{array}$ & $\begin{array}{l}\text { In the face of sudden material demand, whether there is a rapid } \\
\text { distribution team and distribution capability }\end{array}$ \\
\hline & $\begin{array}{l}S_{12}: \text { Emergency reserve } \\
\text { capability }\end{array}$ & Whether there is emergency stock to meet sudden demand \\
\hline \multirow{2}{*}{$\begin{array}{l}\text { Emergency } \\
\text { feedback } \\
\text { capability }\end{array}$} & $\begin{array}{l}S_{13}: \text { Emergency } \\
\text { evaluation and feedback } \\
\text { capability }\end{array}$ & $\begin{array}{l}\text { Whether there are good capability of emergency information } \\
\text { communication, feedback, and evaluation }\end{array}$ \\
\hline & $\begin{array}{l}S_{14}: \text { Aftermath settlement } \\
\text { capability }\end{array}$ & $\begin{array}{l}\text { In the face of emergencies, whether there is the ability to quickly deal } \\
\text { with the aftermath and assess quickly to reduce losses }\end{array}$ \\
\hline
\end{tabular}

$$
X^{1}=X \max _{l \leq i \leq n}\left(\sum_{j=1}^{n} x_{\mathrm{ij}}\right) X^{1}=X \max _{l \leq i \leq n}\left(\sum_{j=1}^{n} x_{\mathrm{ij}}\right)
$$


Figure 3. The process diagram of the methodology

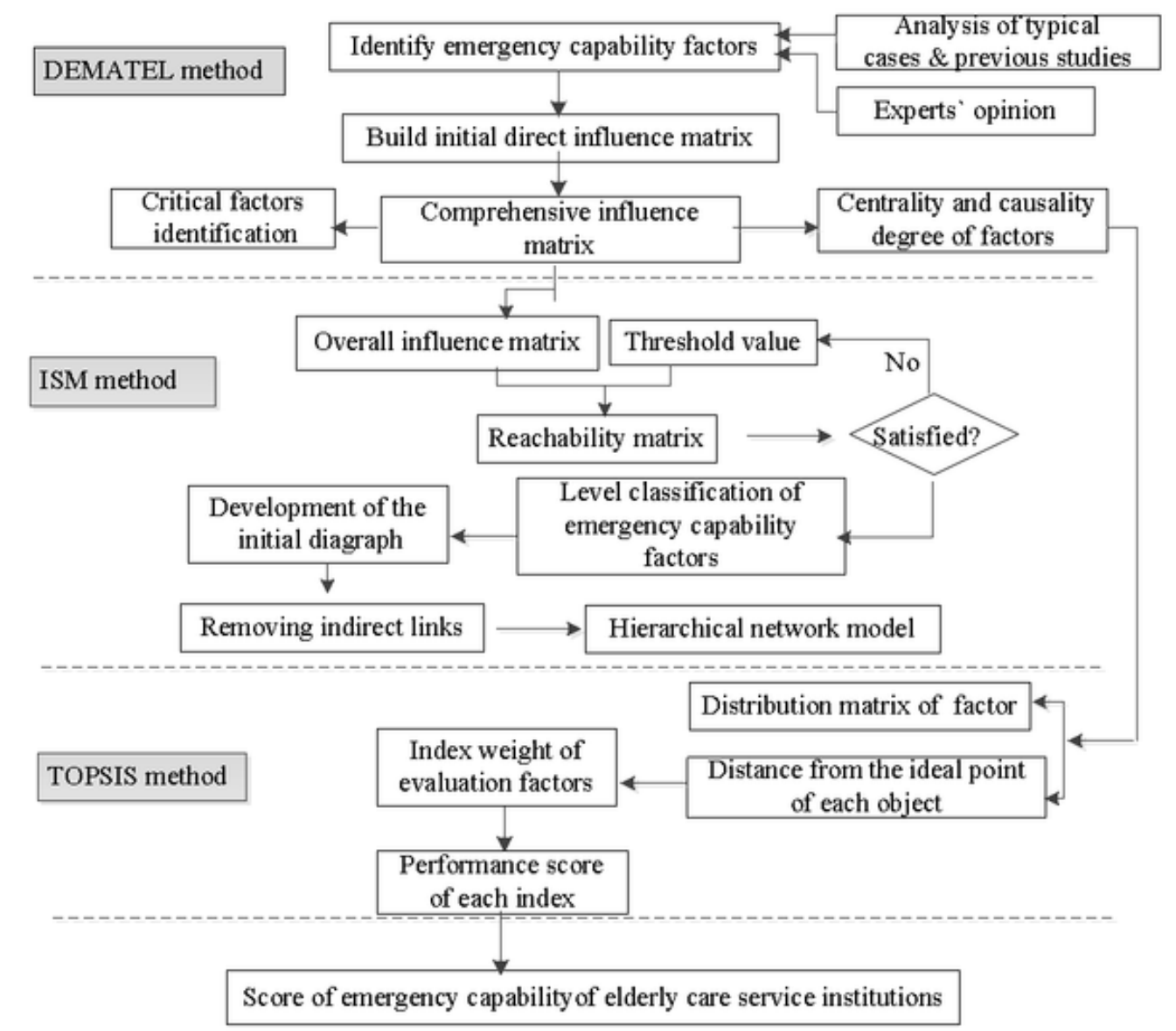

$T=X^{1}\left(I-X^{1}\right)^{-1}=\left(t_{\mathrm{ij}}\right)_{n \times n} T=X^{1}\left(I-X^{1}\right)^{-1}=\left(t_{\mathrm{ij}}\right)_{n \times n}$

Step 3: Calculate the degrees of influence, being influenced, centrality, and causality of decisionmaking evaluation factors

The factors of the matrix $t_{i j} t_{i j}$ are added by rows and columns to obtain the influence degree $F_{i}$ $F_{i}$ and the degree of being influenced $E_{i} E_{i}$ using Eqs. (3)-(4). The degrees of centrality $M_{i}, M_{i}$, and causality $N_{i}, N_{i}$, of the decision-making factors are obtained by the addition and subtraction of the degrees of influence and being influenced of each factor, respectively, using Eqs. (5)-(6).

$F_{i}=\sum_{j=1}^{n} t_{i j},(i=1,2,3, \ldots, n) F_{i}=\sum_{j=1}^{n} t_{i j},(i=1,2,3, \ldots, n)$ 


$$
\begin{aligned}
& E_{i}=\sum_{i=1}^{n} t_{i j},(i=1,2,3, \ldots, n) E_{i}=\sum_{i=1}^{n} t_{i j},(i=1,2,3, \ldots, n) \\
& M_{i}=F_{i}+E_{i} M_{i}=F_{i}+E_{i} \\
& N_{i}=F_{i}-E_{i} N_{i}=F_{i}-E_{i}
\end{aligned}
$$

The degree of influence, $F_{i} E_{i} F_{i}$, represents the comprehensive influence of the factor, $S_{i} S_{i}$, on other factors. The degree of being influenced, $E_{i}$, represents the comprehensive influence of other factors on factor $S_{i} S_{i}$. The degree of centrality $M_{i}, M_{i}$, reflects the importance of the factor in the risk system, where factors with higher degrees of centrality degree are more important. The degree of causality $N_{i}, N_{i}$, reflects the influence of factor $S_{i} S_{i}$ on other factors. The degree of causality $N_{i}>0, N_{i}>0$, indicates that the factor has a great influence on other factors; therefore, it is called the causal factor. The degree of causality $N_{i}<0, N_{i}<0$, indicates that other factors have a great influence on this factor; therefore, it is called the resultant factor.

Step 4: Draw the quadrant distribution of the factor

Taking the degree of causality $N_{i}, N_{i}$, and the degree of centrality, $M_{i} M_{i}$, of each factor as the $\mathrm{X}$ and $\mathrm{Y}$ axis to draw the coordinate graph, the quadrant distribution of the factor is obtained by marking out the coordinate position of each factor. The status and importance of each factor can then be analyzed, combined with the position of each factor in each quadrant.

Step 5: Construct the reachability matrix

The overall influence matrix $H, H$, is obtained by adding the matrix $T, T$, and unit matrix $I$, $I$, using Eq. (7).

$$
H=I+T=\left(h_{\mathrm{ij}}\right)_{n \times n} H=I+T=\left(h_{\mathrm{ij}}\right)_{n \times n}
$$

Given a threshold, $\lambda \lambda$, the reachability matrix, $K=\left(k_{i j}\right)_{n \times n} K=\left(k_{i j}\right)_{n \times n}$, can be derived using Eq. (8).

$$
K=\left(k_{\mathrm{ij}}\right)_{n \times n}, k_{\mathrm{ij}}=\left\{1, h_{\mathrm{ij}} \geq \lambda \mid K=\left(k_{\mathrm{ij}}\right)_{n \times n}, k_{\mathrm{ij}}=\left\{1, h_{\mathrm{ij}} \geq \lambda \mid\right.\right.
$$

$k_{\mathrm{ij}} k_{\mathrm{ij}}$ of the reachability matrix represents the relationship between node $i i$ and node $j k_{\mathrm{ij}}=1 j$. Where $k_{\mathrm{ij}}=1$, there is a connection between nodes $i i$ and $j j$, and $k_{i j}=0 \quad k_{i j}=0$ means there is no connection. Through setting a threshold value, $\lambda \lambda$, minor factors in the influence matrix can be 
filtered out, and the value of $\lambda \lambda$ is assigned $[0,1][0,1]$. The larger the value of $\lambda \lambda$, the more influencing factors will be removed and the clearer the ISM structure model will be. Therefore, the value of $\lambda \lambda$ should be moderate, and the final $\lambda \lambda$ value can be obtained after several tests and modifications.

Step 6: Construct the hierarchical network model of ISM

The reachability matrix $k_{\mathrm{ij}}, k_{\mathrm{ij}}$, can be decomposed to reachable set, $R\left(k_{i}\right)=\left\{S_{j} \in n \mid k_{\mathrm{ij}}=1\right\} R\left(k_{i}\right)=\left\{S_{j} \in n \mid k_{\mathrm{ij}}=1\right\}$, and antecedent set $Q\left(k_{i}\right)=\left\{S_{j} \in n \mid k_{\mathrm{ij}}=1\right\}, Q\left(k_{i}\right)=\left\{S_{j} \in n \mid k_{\mathrm{ij}}=1\right\}$, and the common factor can be extracted from these sets according to Eq. $A=\left\{S_{j} \in n \mid R\left(k_{i}\right) \cap Q\left(k_{i}\right)=R\left(k_{i}\right), i=0,1, \ldots n\right\}$ (9).

The top-level factors are extracted in the first level as Eq. (9), and a new reachable matrix $k^{1}$, $k^{1}$, is obtained through deleting the corresponding rows and columns of factors extracted from the first level of the original reachability matrix. The above operations are repeated to establish the factors in the second level and so on until all factors are extracted to determine the factor of the lowest level, and then the ISM structure model can be drawn according to these extracted factors.

Step 7: Evaluate factors by TOPSIS

Taking the values of $M_{i} M_{i}$ and $N_{i} N_{i}$ as the element of the evaluation matrix $\boldsymbol{X}^{*} \boldsymbol{X}^{*}$ :

$$
X^{*}=\left[\begin{array}{cc}
M_{1} & N_{1} \\
M_{2} & N_{2} \\
\vdots & \vdots \\
M_{n} & N_{\mathrm{n}}
\end{array}\right] X^{*}=\left[\begin{array}{cc}
M_{1} & N_{1} \\
M_{2} & N_{2} \\
\vdots & \vdots \\
M_{n} & N_{\mathrm{n}}
\end{array}\right]
$$

As the dimensions of the values of $M_{i} M_{i}$ and $N_{i} N_{i}$ are not uniform, the data is standardized to obtain a standardized matrix, $Z Z$, where $Z_{i j} Z_{i j}$ is the element in the matrix. The distances between each evaluation object and the ideal solution and between each evaluation object and the worst solution are calculated to obtain the $L_{i}^{+} L_{i}^{+} L_{i}^{-} L_{i}^{-}$. The calculation formulas are as follows:

$$
\begin{aligned}
& L_{i}^{+}=\sqrt{\sum_{j=1}^{m}\left(\max z_{i j}-z_{i j}\right)^{2}} L_{i}^{+}=\sqrt{\sum_{j=1}^{m}\left(\max z_{i j}-z_{i j}\right)^{2}} \\
& L_{i}^{-}=\sqrt{\sum_{j=1}^{m}\left(\min z_{i j}-z_{i j}\right)^{2}} L_{i}^{-}=\sqrt{\sum_{j=1}^{m}\left(\min z_{i j}-z_{i j}\right)^{2}}
\end{aligned}
$$


By calculating the closeness of ideal solution $L_{i}=\frac{L_{i}^{-}}{L_{i}^{-}+L_{i}^{+}} L_{i}=\frac{L_{i}^{-}}{L_{i}^{-}+L_{i}^{+}}$, it is simply to obtain $0 \leq L_{i} \leq 10 \leq L_{i} \leq 1$, and the larger the $L_{i} L_{i}$, the higher the weight of the indicator. To score the performance of each evaluation unit and establish the score of each indicator as $y_{i} y_{i}$, the total score of the evaluation unit is calculated as follows:

$$
Y=y_{i} L_{i}^{*} Y=y_{i} L_{i}^{*}
$$

\section{EVALUATION AND ANALYSIS}

\subsection{Obtaining the direct influence matrix}

0 to 5 are used to indicate different levels of influence, among which, 0 means almost no influence, and 5 means a strong influence. The interviewees were invited to score the evaluation indicators, and the evaluation matrix, was obtained by averaging the scoring results of respondents. A total of 11 elderly care service institutions were investigated, and 86 evaluations were collected. Among the 11 institutions surveyed, five of them are from Guangzhou, three from Dongguan, and three from Shenzhen, in the 1-5-score evaluation of elderly care service institutions launched by the Guangdong Provincial Department of Civil Affairs. These elderly care service institutions are all authorized by three-star qualification. Among the respondents, $22.3 \%$ were employees of elderly care service institutions, $18.7 \%$ were customers of elderly care service institutions, $36.8 \%$ were from universities and research institutions, $13.8 \%$ were officials of government departments of elderly services, and $8.4 \%$ were family members of the elderly and others.

\subsection{Analysis on the Attributes of Influencing Factors}

According to Eqs. (1)-(6), the degree of influence $F_{i}, F_{i}$; the degree of being influenced, $E_{i} E_{i}$; the degree of centrality $M_{i}, M_{i}$; and the degree of causality $N_{i}, N_{i}$, of each factor in emergency response capability were obtained, as shown in Table 2.

The degree of centrality of the factor reflects its importance in emergency capability. The degree of causality indicates the influence relationship between factors of the emergency capability and others. When the degree of causality degree is greater than 0 , it can be called the causal factor, as it shows that it has a great influence on other factors. When the degree of causality is less than 0 , it can be called the resultant factor, which indicates that the factor is greatly influenced by other factors.

\subsection{Quadrant distribution of the factors of emergency capability}

The quadrant distribution of the factors of the emergency capability of the elderly services supply chain is shown in Figure 4.

\subsection{Evaluation of Emergency Capability}

DEMATEL compares the factors in the decision-making evaluation matrix in pairs to obtain the degrees of centrality and causality. After normalization and standardization, $S_{1}$ and $S_{1}$ were calculated by the TOPSIS method, and the approximate ideal solution value of each evaluation factor $S_{7}, S_{7}$, was obtained, which is used as the weight of each factor after normalization. The weight value of indicators and the initial score of the emergency capability are shown in Table 3. 
Table 2. Degree of influence, degree of being influenced, degree of centrality, and degree of causality

\begin{tabular}{|c|c|c|c|c|c|c|c|c|c|c|c|c|c|c|}
\hline Factor & $S_{\mathbf{1}}$ & $S_{\mathbf{2}}$ & $S_{\mathbf{3}}$ & $S_{\mathbf{4}}$ & $S_{\mathbf{5}}$ & $S_{\mathbf{6}}$ & $S_{\mathbf{7}}$ & $S_{\mathbf{8}}$ & $S_{\mathbf{9}}$ & $S_{10}$ & $S_{\mathbf{1 1}}$ & $S_{\mathbf{1 2}}$ & $S_{\mathbf{1 3}}$ & $S_{\mathbf{1 4}}$ \\
\hline & 1.75 & 1.28 & 2.01 & 1.76 & 1.52 & 1.83 & 1.16 & 1.45 & 1.66 & 1.04 & 1.3 & 0.93 & 0.87 & 0.96 \\
\hline & 0.28 & 0.85 & 1.28 & 1.62 & 1.96 & 1.39 & 0.75 & 0.88 & 1.1 & 0.53 & 1.2 & 0.75 & 1.43 & 1.31 \\
\hline & 6.92 & 6.28 & 5.97 & 6.45 & 7.06 & 6.97 & 7.43 & 6.75 & 8.73 & 7.68 & 7.22 & 6.39 & 5.32 & 5.5 \\
\hline & 1.73 & -0.35 & -0.32 & 0.44 & -0.21 & -0.55 & 0.33 & -0.28 & 0.23 & 0.63 & -0.5 & -0.36 & 0.06 & -0.85 \\
\hline
\end{tabular}

Figure 4. Quadrant distribution of the factors of the emergency capability of the elderly services supply chain

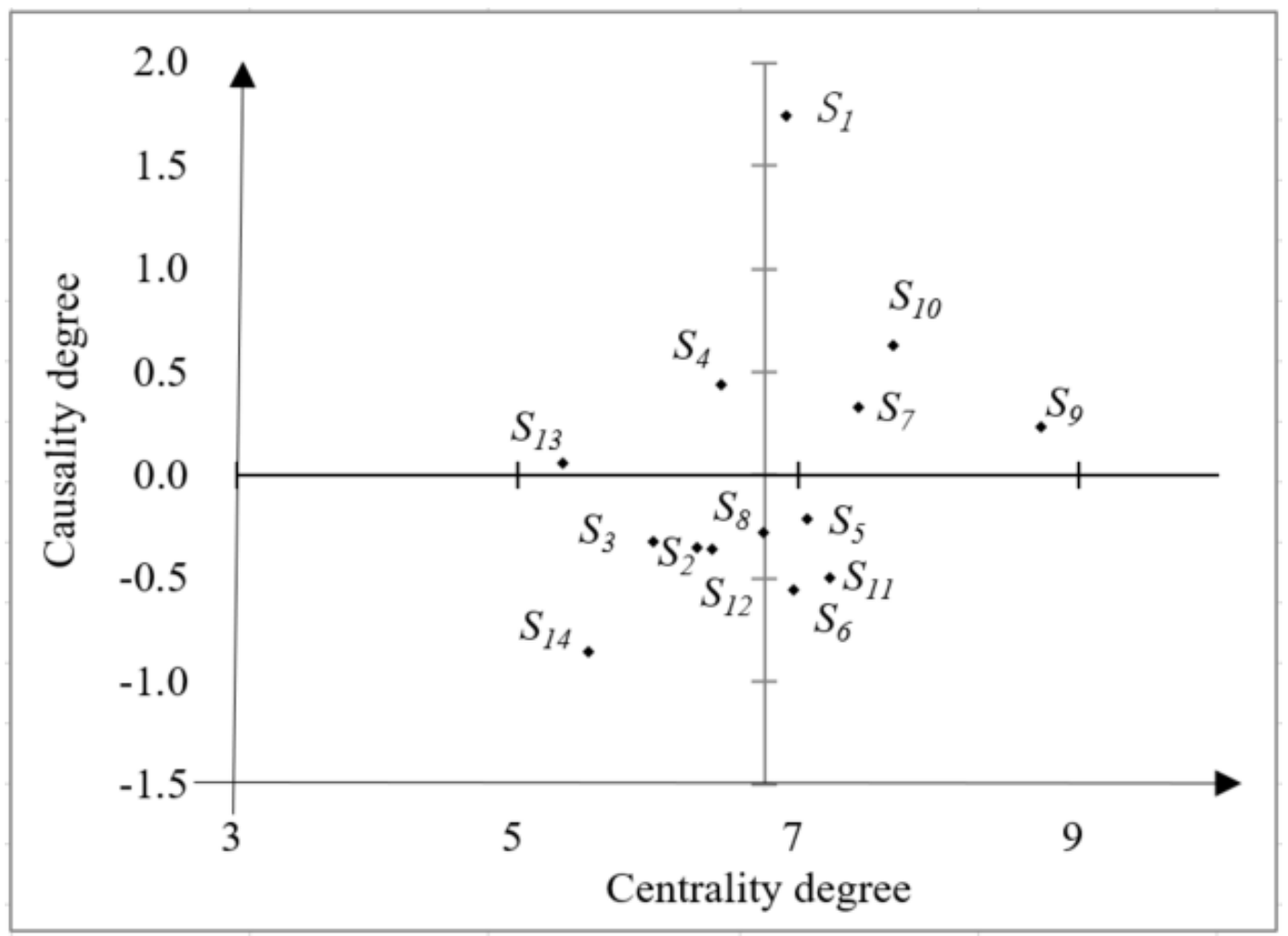

The research team conducted a survey on 11 elderly care institutions, selected the evaluation scores of three of them to summarize, and combined them with the weights shown in Table 3 to calculate their first-level indicator scores and total scores, as shown in Table 4.

\section{RESULTS AND DISCUSSION}

According to the results in Table 2, the influencing factors of the emergency capability of the elderly services supply chain whose degree of causality is greater than 0 are as follows: $S_{9} S_{9} S_{4} S_{4} S_{2} S_{2}$ $S_{3}, S_{3}, S_{12}, S_{12}, S_{5}$, and $S_{5}$, namely, the design of the emergency response plan, emergency information monitoring capability, emergency supply replenishment rate, emergency rescue capability, 
Figure 5. ISM model of influential factors for the elderly services supply chain

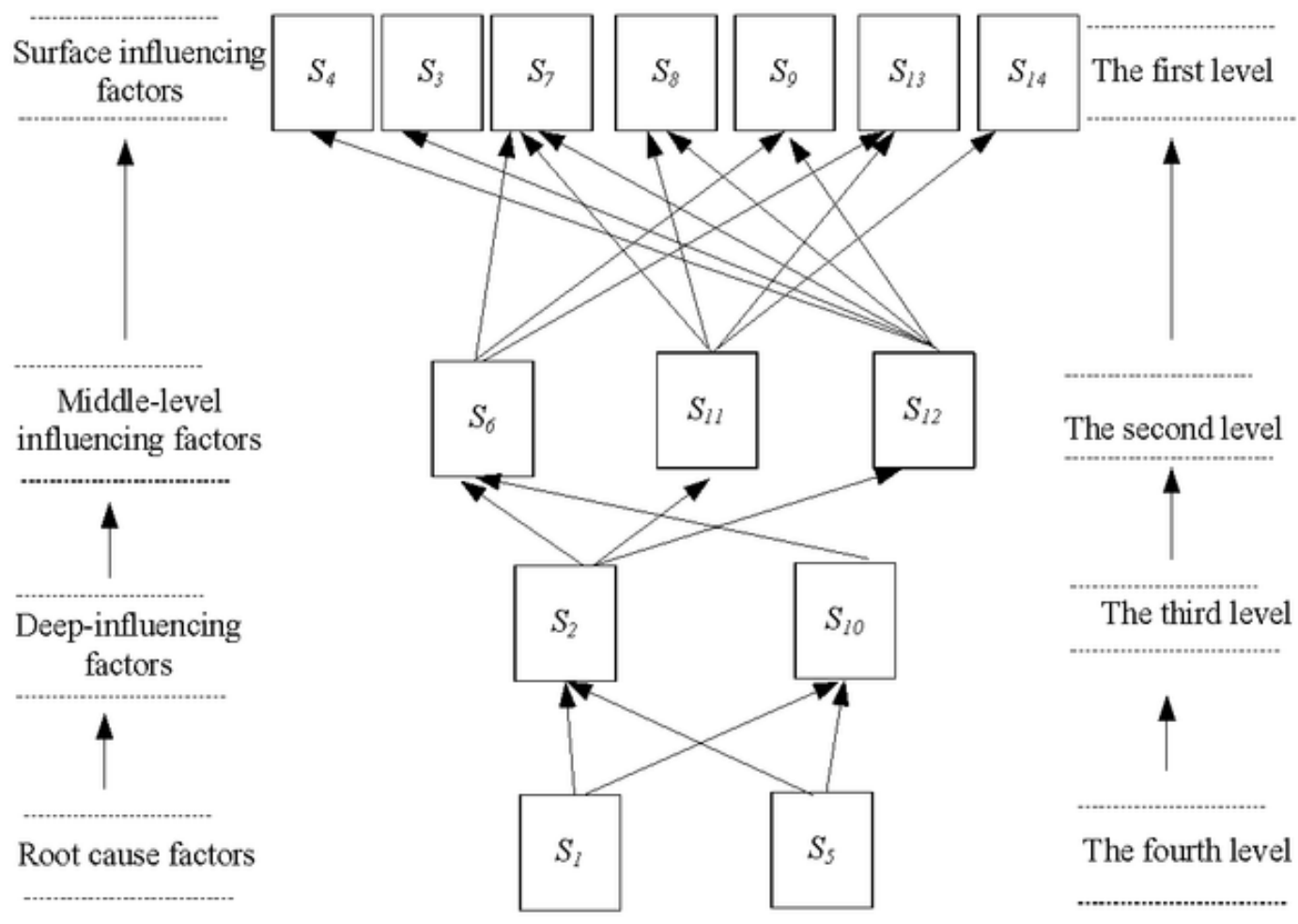

Table 3. Weight value of indicators and the initial score of emergency capability

\begin{tabular}{|c|c|c|c|c|c|c|c|c|c|c|c|c|c|c|}
\hline Factor & $S_{1}$ & $S_{2}$ & $S_{3}$ & $S_{4}$ & $S_{5}$ & $S_{6}$ & $S_{7}$ & $S_{8}$ & $S_{9}$ & $S_{10}$ & $S_{11}$ & $S_{12}$ & $S_{13}$ & $S_{14}$ \\
\hline & 0.29 & 0.38 & 0.41 & 0.25 & 0.28 & 0.37 & 0.14 & 0.32 & 0.19 & 0.05 & 0.34 & 0.37 & 0.45 & 0.56 \\
\hline & 0.70 & 0.20 & 0.17 & 0.37 & 0.32 & 0.27 & 0.45 & 0.27 & 0.61 & 0.53 & 0.32 & 0.21 & 0.23 & 0.03 \\
\hline & 0.71 & 0.34 & 0.29 & 0.60 & 0.53 & 0.43 & 0.77 & 0.45 & 0.76 & 0.91 & 0.48 & 0.36 & 0.34 & 0.05 \\
\hline Weight & 0.10 & 0.05 & 0.04 & 0.09 & 0.08 & 0.06 & 0.11 & 0.06 & 0.11 & 0.13 & 0.07 & 0.05 & 0.05 & 0.01 \\
\hline
\end{tabular}

emergency medical service capability, and emergency feedback and evaluation capability. These six factors have a great influence on other factors, and they are the causal factors of the decision evaluation matrix. In addition, the other eight factors are called resultant factors, which are greatly influenced by the six factors above.

The ranking of the factors according to the centrality degree is as follows $S_{6}: S_{6}>S_{8} S_{8}>S_{11}$ $S_{11}>\lambda=0.31 \lambda=0.31 L_{i}^{+} L_{i}^{+}>L_{i}^{-} L_{i}^{-} L_{i}>L_{i} S_{1}>S_{4} S_{7}>S_{9} S_{10}>S_{13} S_{1}>S_{4} S_{7}>S_{9} S_{10}>S_{13} S_{9}$ $>S_{9} S_{10}>S_{10} S_{7}>S_{7} S_{11}$. The degree of centrality reflects the importance of the evaluation factors in the capability of the elderly services supply chain. There are seven factors whose degrees of importance are above average: the emergency rescue capability, emergency medical service capability, emergency supply preparation capability, emergency distribution capability, organizational capability of emergency personnel, emergency medical coordination capability, and design of the emergency 
Table 4. Evaluation score of the emergency response capability of three elderly services institutions

\begin{tabular}{|l|l|l|l|}
\hline \multicolumn{1}{|c|}{ First-level indicators } & \multicolumn{1}{c|}{ Institution A } & \multicolumn{1}{c|}{ Institution B } & \multicolumn{1}{c|}{ Institution C } \\
\hline Emergency design capability & 0.53 & 0.54 & 0.94 \\
\hline Emergency planning capability & 0.91 & 0.87 & 1.31 \\
\hline Emergency supply capability & 1.28 & 1.25 & 1.08 \\
\hline Emergency delivery capability & 1.13 & 1.11 & 0.26 \\
\hline Emergency feedback capability & 0.25 & 0.24 & 4.17 \\
\hline Total score & 4.10 & 4.01 & \\
\hline
\end{tabular}

response plan. It shows that these factors play a leading role in the emergency capability of the elderly services supply chain.

According to the quadrant distribution diagram of the levels of emergency capability (Figure 3), it can be seen that the key factors of great importance and that have a great influence on other factors are the design of the emergency response plan $\left(S_{11} S_{5}\right)$, the emergency supply replenishment rate ( $S_{5} S_{6}$ ), the emergency rescue capability ( $S_{6} S_{1}$ ), and the emergency medical service capability ( $S_{1}$ $\left.S_{8}\right)$.

According to the ISM model (Figure 4), $S_{8} S_{4}$ and $S_{4} S_{12}$ are at the bottom, which indicates that the design of the emergency response plan and the organization capability of emergency personnel are the core and essential influencing factors. The factors $S_{12} S_{2} S_{2}, S_{3}, S_{3} S_{4}, S_{4} S_{14} S_{14}, S_{13}$, $S_{13} S_{13}$, and $S_{13} S_{7}$ are at the top level, which means they directly affect the emergency response capability of the elderly services supply chain. The factors in the second and third level, $S_{7} S_{9}, S_{9}$ $S_{10}, S_{10} S_{1}$, and $S_{1} S_{5}$, are the intermediate influencing factors of the emergency capability of the elderly services supply chain. These factors do not directly affect the emergency capability of the elderly services supply chain but rather have an indirect influence through the top-level factors.

In past research on emergency management of the elderly, more attention has been paid to the content of emergency medical care, such as the proportion of emergency medical care being used (Platts-Mills et al., 2010), the main reasons for why emergency medical care is needed (Lee et al., 2017), and how to improve emergency medical capability (Gill et al., 2016; Tang et al., 2019). This research studied the emergency capability indicators of elderly care services from the perspective of the supply chain. By establishing the emergency capability of three elderly care institutions, it was found that emergency supply and delivery capability were the best-performing, top-level indicators. The scores of three second-level indicators indicated that the emergency medical service capability, emergency supply replenishment rate, and emergency rescue response capability were less influential. This is related to the existing research and tendency to pay more attention to the emergency medical treatment and rescue of the elderly. The two first-level indicators, emergency design capability and emergency feedback, performed poorly. This is mainly because agencies have not yet established and improved emergency management systems from the perspective of the entire supply chain.

Through the above analysis, the attributes, importance, and hierarchical structure of the factors in the emergency capability of the elderly services supply chain are more deeply and clearly understood. According to the score and analysis of factors, it is helpful to put forward targeted measures to improve the emergency capability. In accordance with the analysis results, more attention should be paid to the following aspects to improve the emergency response capability of elderly services: 
(1) The formulation and design of emergency plans for elderly services should be strengthened and perfected, and the organizational capability of emergency personnel should be improved through regular drills to find problems in emergency management.

(2) Standardized risk prevention guidelines should be established to classify risks, establish plans and countermeasures, and strengthen the monitoring of risk factors.

(3) A good relationship with medical institutions should be built to improve the replenishment rate of emergency supply, emergency rescue response capability, emergency medical services, and other key influencing factors. An elderly care management system based on the IoMT should be developed. The sharing of information and data on the elderly should be shared between medical institutions and elderly care institutions, and the storage, retrieval, and reuse of data for medical and health information services for the elderly should be implemented.

(4) It is necessary to strengthen the ability of information collection and analysis as well as early warnings for risks, and build a new rapid feedback and processing mechanism.

(5) A backup supplier team for the supply of key goods should be established in the future.

\section{CONTRIBUTIONS AND IMPLICATIONS}

The supply chain theory was first applied in the industrial field. With the intersection of disciplines, numerous subresearch fields have been derived. Supply chain innovation has become all the more important in today's competitive world. The elderly care services supply chain theory is a new research field derived from the combination of traditional supply chain and service industry. The emergency capability of the elderly care services supply chain that this research focuses on is a subsystem of the combination of the elderly services and supply-chain theories. The current research on the emergency management of the elderly mainly emphasizes the field of emergency medical treatment, and there is no literature analyzing the emergency capability of elderly care services from the perspective of the supply chain. This research can further improve the emergency management theory of elderly care services, broaden the scope of research in the field of service supply chains, and have great supplementary significance to the theory of elderly care services in emergencies. In terms of research methods, the integrated DEMATEL-ISM-TOPSIS method combines the main advantages of DEMATEL, ISM, and TOPSIS. It is a hybrid and diversified decision-making evaluation method and an innovative research methodology.

The trend of global aging is becoming more and more obvious. The aging of the Chinese population is accelerating. On average, one out of every four elderly people is in China. The market scale of China's elderly care service industry is growing rapidly. The elderly care service system does not simply provide elderly care services but also includes a multi-faceted organic system, such as service design, service supply, quality supervision, and customer service. The elderly, the object of elderly care services, are characterized by many sudden diseases and diverse needs for their care. The diversity and personalization of health care services for the elderly are of paramount importance. The requirements for elderly care service products are more complex than other types of services and products, leading to higher demand fluctuations. Research showed that $71.3 \%$ of the respondents have low emergency response capability when emergencies occur in elderly care institutions. Analyzing and researching the emergency capability of elderly care services will help to find the weak links and take targeted measures for prevention. A forward-looking study on the emergency capability of the elderly care services supply chain is conducive to building an emergency management system for elderly care services and guaranteeing the ultimate rights and interests of the elderly are upheld. It can provide a theoretical reference and basis for elderly care SIs and participating companies to improve their supply chain capability and ensure the stability of the elderly care services supply chain. Moreover, it has a guiding role for the government and elderly care service agencies to build an emergency system and evaluation mechanism for such services. 


\section{CONCLUSION}

Although the concept of the services supply chain has gradually emerged and been used to analyze various service industries, the existing literature rarely analyzes the elderly services industry from the perspective of the supply chain. This paper first proposes to build an evaluation indicator model of the emergency capability of the elderly services supply chain from the perspective of the SCOR model. Based on the advantages of the DEMATEL and ISM models, the existing literature often adopts the integrated DEMATEL-ISM method for research. This study proposes an integrated DEMATELISM-TOPSIS method, which synthesizes the main advantages of the three methods. The degree of centrality that reflects the importance and effect of factors in the emergency capability of the elderly services supply chain was calculated, as well as the degree of causality, which reflects the influence of evaluated factors on other factors, according to the empirical analysis based on the data of elderly care institutions in the Pearl River Delta of China. Through this method, the degree of influence of key factors and the causal relationship between them are clarified to determine which are the most important, which are surface-level factors, and which are deep-seated. The quadrant distribution diagram of each factor was drawn with the degrees of centrality and causality degree of each factor as the coordinates. The factors in emergency capability were divided into four quadrants: the key, resultant, conventional, and influencing factors. This paper analyzes and identifies the factors in the emergency capability of elderly services from the perspective of the supply chain, which is beneficial to identify the weak links in emergency capability to take targeted and preventive measures. The research can also provide scientific guidance for the supply chain and emergency management of elderly services to improve their emergency and management capability. According to the evaluation index model of the emergency capability of the elderly services supply chain, the emergency capabilities of three elderly services institutions were evaluated, which showed that the evaluation index model and the DEMATEL-ISM-TOPSIS method are scientific and applicable. The emergency response capability of the elderly services supply chain will need to be tested in practice over a long period. In the future, more detailed discussion and research can be conducted based on the feedback of actual operation and management, such as discussing the components of emergency response capability in more detail and studying the emergency response mechanism of elderly services.

Funding: This research was funded by Guangdong Basic and Applied Basic Research Foundation (2019A1515110909), Guangdong Education Science Planning Project (2021GXJK120), and Shenzhen Philosophy and Social Science Planning Project (SZ2020A007).

Conflicts of Interest: The authors declare no conflict of interest. 


\section{REFERENCES}

Alam-Tabriz, A., Rajabani, N., \& Farrokh, M. (2014). An integrated Fuzzy DEMATEL-ANP-TOPSIS methodology for supplier selection problem. Global Journal of Management Studies and Researches, 1(2), 85-99.

Baltacioglu, T., Ada, E., Kaplan, M. D., Yurt And, O., \& Cem Kaplan, Y. (2007). A new framework for service supply chains. Service Industries Journal, 27(2), 105-124. doi:10.1080/02642060601122629

Cao, L., Feng, J. C., \& Ren, Y. (2018). Risk Evaluation of EPC supply chain based on SCOR and multi-level grey model: A case study of China's waste incineration plant project. International Journal of Information Systems and Supply Chain Management, 11(2), 54-76. doi:10.4018/IJISSCM.2018040104

Chang, D. S., Liu, S. M., \& Chen, Y. C. (2017). Applying DEMATEL to assess TRIZ's inventive principles for resolving contradictions in the long-term care cloud system. Industrial Management \& Data Systems, 117(6), 1244-1262. doi:10.1108/IMDS-06-2016-0212

Chau, K., Tang, Y. M., Liu, X., Ip, Y.-K., \& Tao, Y. (2021, February 08). LP, Y. \& Tao, Y. (2021). Investigation of critical success factors for improving supply chain quality management in manufacturing. Enterprise Information Systems, 1-20. Advance online publication. doi:10.1080/17517575.2021.1880642

Chehbi-Gamoura, S., Derrouiche, R., Damand, D., \& Barth, M. (2020). Insights from big Data Analytics in supply chain management: An all-inclusive literature review using the SCOR model. Production Planning and Control, 31(5), 355-38. doi:10.1080/09537287.2019.1639839

Cui, F., Ma, L., Hou, G., Pang, Z., Hou, Y., \& Li, L. (2020). Development of smart nursing homes using systems engineering methodologies in industry 4.0. Enterprise Information Systems, 14(4), 463-479. doi:10.1080/175 17575.2018.1536929

Dwivedi, Y. K., Shareef, M. A., Mukerji, B., Rana, N. P., \& Kapoor, K. K. (2018). Involvement in emergency supply chain for disaster management: A cognitive dissonance perspective. International Journal of Production Research, 56(21), 6758-6773. doi:10.1080/00207543.2017.1378958

Gao, Y., \& Zhou, S. (2020). On the cooperation mechanism of elderly service system with different level and cross-Chain. 35th Youth Academic Annual Conference of Chinese Association of Automation. doi:10.1109/ YAC51587.2020.9337504

Gill, A. Q., Phennel, N., Lane, D., \& Phung, V. L. (2016). IoT-enabled emergency information supply chain architecture for elderly people: The Australian context. Information Systems, 58(6), 75-86. doi:10.1016/j. is. 2016.02 .004

He, J., \& Wang, P. (2019). Research on supply-side management of pension service industry under rapidly aging. Advances in Sciences and Humanities, 5(5), 114. doi:10.11648/j.ash.20190505.11

Hong, J. D., Jeong, K. Y., \& Feng, K. (2015). Emergency relief supply chain design and trade-off analysis. Journal of Humanitarian Logistics and Supply Chain Management, 5(2), 162-187. doi:10.1108/JHLSCM-05-2014-0019

Huang, C. W. (2018). Assessing the performance of tourism supply chains by using the hybrid network data envelopment analysis model. Tourism Management, 65, 303-316. doi:10.1016/j.tourman.2017.10.013

Iyamu, T., \& Shaanika, I. (2020). Factors influencing the use of mobile systems to access healthcare big data in a namibian public hospital. Information Resources Management Journal, 33(3), 81-99. doi:10.4018/ IRMJ.2020070104

Jahre, M., Kembro, J., Rezvanian, T., Ergun, O., Håpnes, S. J., \& Berlingbe, P. (2016). Integrating supply chains for emergencies and ongoing operations in UNHCR. Journal of Operations Management, 45(7), 57-72. doi:10.1016/j.jom.2016.05.009

Ji, G. J., \& Zhu, C. H. (2012). A study on emergency supply chain and risk based on urgent relief service in disasters. Systems Engineering Procedia, 5, 313-325. doi:10.1016/j.sepro.2012.04.049

Kilic, H. S., \& Yalcin, A. S. (2020). Comparison of municipalities considering environmental sustainability via neutrosophic DEMATEL based TOPSIS. Socio-Economic Planning Sciences, 6(3), 100827. doi:10.1016/j. seps.2020.100827 
Kim, S. O., \& Bae, S. H. (2020). Emergencies in long-term care services for the elderly in Korea: A mixedmethods study. International Journal of Environmental Research and Public Health, 17(1), 66. doi:10.3390/ ijerph17010066 PMID:31861787

Kumar, A., \& Dixit, G. (2018). An analysis of barriers affecting the implementation of e-waste management practices in India: A novel ISM-DEMATEL approach. Sustainable Production and Consumption, 14(4), 36-52. doi:10.1016/j.spc.2018.01.002

Lam, H. Y., Ho, G. T. S., Mo, D. Y., \& Tang, V. (2021). Enhancing data-driven elderly appointment services in domestic care communities under COVID-19. Industrial Management \& Data Systems, 121(7), 1552-1576. doi:10.1108/IMDS-07-2020-0392

Lee, S., Lee, C., \& Rodiek, S. (2017). Neighborhood factors and fall-related injuries among older adults seen by emergency medical service providers. International Journal of Environmental Research and Public Health, 14(2), 163. doi:10.3390/ijerph14020163 PMID:28208748

Leung, K. H., Lau, H. C. W., Nakandala, D., Kong, X. T. R., \& Ho, G. T. S. (2021). Standardising fresh produce selection and grading process for improving quality assurance in perishable food supply chains: An integrated Fuzzy AHP-TOPSIS framework. Enterprise Information Systems, 15(5), 651-675. doi:10.1080/17517575.20 20.1790041

Li, F., Wang, W., Dubljevic, S., Khand, F., Xu, J., \& Yi, J. (2019). Analysis on accident-causing factors of urban buried gas pipeline network by combining DEMATEL, ISM and BN methods. Journal of Loss Prevention in the Process Industries, 61, 49-57. doi:10.1016/j.jlp.2019.06.001

Liu, W., Wang, D., Long, S., Shen, X., \& Shi, V. (2019). Service supply chain management: A behavioural operations perspective. Modern Supply Chain Research and Applications, 1(1), 28-53. doi:10.1108/ MSCRA-01-2019-0003

Liu, X., Zhang, K., Chen, B., Zhou, J., \& Miao, L. (2018). Analysis of logistics service supply chain for the one belt and one road initiative of China. Transportation Research Part E, Logistics and Transportation Review, 117, 23-29. doi:10.1016/j.tre.2018.01.019

Mandal, S. (2016). A social-exchange perspective on supply chain innovation. International Journal of Information Systems in the Service Sector, 8(3), 36-57. doi:10.4018/IJISSS.2016070103

Melnyk, S. A., Narasimhan, R., \& DeCampos, H. A. (2014). Supply chain design: Issues, challenges, frameworks and solutions. International Journal of Production Research, 52(7), 1887-1896. doi:10.1080/00207543.2013 .787175

Menghi, R., Papetti, A., \& Germani, M. (2019). Product service platform to improve care systems for elderly living at home. Health Policy and Technology, 8(4), 393-401. doi:10.1016/j.hlpt.2019.10.004

Mezouar, H., \& Afia, A. E. (2018). Performance analysis model for service supply chains: Case of the retirement supply chain. IACSIT International Journal of Engineering and Technology, 7(3), 1429-1438. doi:10.14419/ ijet.v7i3.13929

Mohammed, A., Naghshineh, B., Spiegler, V., \& Carvalho, H. (2021). Conceptualising a supply and demand resilience methodology: A hybrid DEMATEL-TOPSIS-possibilistic multi-objective optimization approach. Computers \& Industrial Engineering, 160, 107589. doi:10.1016/j.cie.2021.107589

Ntabe, E. N., LeBel, L., Munson, A. D., \& Santa-Eulalia, L. A. (2015). A systematic literature review of the Supply Chain Operations Reference (SCOR) model application with special attention to environmental issues. International Journal of Production Economics, 169, 310-332. doi:10.1016/j.ijpe.2015.08.008

Okwu, M. O., \& Tartibu, L. K. (2020). Sustainable supplier selection in the retail industry: A TOPSIS- and ANFIS-based evaluating methodology. International Journal of Engineering Business Management, 12, 1-14. doi: $10.1177 / 1847979019899542$

Platts-Mills, T. F., Leacock, B., Cabañas, J. G., Shofer, F. S., \& McLean, S. A. (2010). Emergency medical services use by the elderly: Analysis of a statewide database. Prehospital Emergency Care, 14(3), 329-333. do i:10.3109/10903127.2010.481759 PMID:20507220 
Putthinoi, S., Meksamoot, K., Yodmongkol, P., \& Chakpitak, N. (2015). Household reverse logistics analysis using the SCOR model to improve home safety of the elderly in the municipality. International Journal of Logistics Systems \& Management, 21(3), 348. doi:10.1504/IJLSM.2015.069732

Raghunath, K. M. K., \& Devi, S. L. T. (2018). Supply chain risk management: An invigorating outlook. International Journal of Information Systems and Supply Chain Management, 11(3), 87-104. doi:10.4018/ IJISSCM.2018070105

Rahi, S., Khan, M. M., \& Alghizzawi, M. (2021). Factors influencing the adoption of telemedicine health services during COVID-19 pandemic crisis: An integrative research model. Enterprise Information Systems, 15(6), 769-793. doi:10.1080/17517575.2020.1850872

Raut, R., Narwane, V., Kumar Mangla, S., Yadav, V. S., Narkhede, B. E., \& Luthra, S. (2021). Unlocking causal relations of barriers to big data analytics in manufacturing firms. Industrial Management \& Data Systems, 121(9), 1939-1968. Advance online publication. doi:10.1108/IMDS-02-2020-0066

Sharma, S. K., Bhat, A., Kumar, V., \& Agarwal, A. (2017). Path analysis model for supply chain risk management. International Journal of Information Systems and Supply Chain Management, 10(2), 21-41. doi:10.4018/ IJISSCM.2017040102

Stewart, G. (1997). Supply-chain operations reference model (SCOR): The first cross-industry framework for integrated supply-chain management. Logistics Information Management, 10(2), 62-67. doi:10.1108/09576059710815716

Supromin, C., \& Choonhakhlai, S. (2019). The provision of public services in municipalities in thailand to improve the quality of life of elderly people. Kasetsart Journal of Social Sciences, 40, 619-627. doi:10.1016/j. kjss.2017.12.011

Tang, V., Choy, K. L., Ho, G. T. S., Lam, H. Y., \& Tsang, Y. P. (2019). An IoMT-based geriatric care management system for achieving smart health in nursing homes. Industrial Management \& Data Systems, 119(8), 1819-1840. doi:10.1108/IMDS-01-2019-0024

Thomas, V. A., \& Mahanty, B. (2020). Assessment of emergency sourcing strategy of a supply chain through dynamic simulation approach. Journal of Industrial and Production Engineering, 37(1), 56-69. doi:10.1080/ 21681015.2020.1729877

Tooranloo, H. S., Karimi, S., \& Vaziri, K. (2018). Analysis of the factors affecting sustainable electronic supply chains in healthcare centers: An interpretive-structural modeling approach. Information Resources Management Journal, 31(4), 23-43. doi:10.4018/IRMJ.2018100102

Trivedi, A., Jakhar, S. K., \& Sinha, D. (2021). Analyzing barriers to inland waterways as a sustainable transportation mode in India: A DEMATE- ISM based approach. Journal of Cleaner Production, 295, 126301. doi:10.1016/j.jclepro.2021.126301

Wang, L., Cao, Q., \& Zhou, L. (2018). Research on the influencing factors in coal mine production safety based on the combination of DEMATEL and ISM. Safety Science, 103, 51-61. doi:10.1016/j.ssci.2017.11.007

Yazdi, M., Khan, F., Abbassi, R., \& Rusli, R. (2020). Improved DEMATEL methodology for effective safety management decision-making. Safety Science, 127(7), 104705. doi:10.1016/j.ssci.2020.104705

Zhao, J. (2020). Coordination of elderly healthcare service supply chain with information asymmetry: Designs of option contracts under different demand distribution statuses. Operations Research, 54(5), 1291-1307. doi:10.1051/ro/2019032

Zhao, J. (2021). Sustainability on the service capacity in elderly healthcare service supply chains: An application of flexible contracts. IEEE Transactions on Engineering Management, 5, 1-11. doi:10.1109/TEM.2021.3071587

Jingshi He was born in Yongzhou, Hunan, China, in 1984. He is currently working in Business College, Dong Guan Polytechnic, China, and was appointed as associate professor. His research interests include services supply chain.

Jiali Zhu was born in Yixing, Jiangsu, China, in 1985. She is currently working in Department of Logistics Engineering, Dong Guan Polytechnic, China. 